\title{
A CONTROLLED STUDY OF ADENOVIRAL-VECTOR-MEDIATED GENE TRANSFER IN THE NASAL EPITHELIUM OF PATIENTS WITH GYSTIC FIBROSIS
}

\author{
Michael R. Knowles, M.D., Kathy W. Hohneker, R.N., Zhaoqing Zhou, Ph.D., John C. Olsen, Ph.D., \\ Terry L. Noah, M.D., Ping-Ghuan Hu, Ph.D., Margaret W. Leigh, M.D., John F. Engelhardt, Ph.D., \\ Lloyd J. Edwards, Ph.D., Kim R. Jones, M.D., Ph.D., Mariann Grossman, B.S., \\ James M. Wilson, M.D., Ph.D., Larry G. Johnson, M.D., and Richard C. Boucher, M.D.
}

\begin{abstract}
Background. Cystic fibrosis is a monogenic disease that deranges multiple systems of ion transport in the airways, culminating in chronic infection and destruction of the lung. The introduction of a normal copy of the cystic fibrosis transmembrane conductance regulator (CFTR) gene into the airway epithelium through gene transfer is an attractive approach to correcting the underlying defects in patients with cystic fibrosis. We tested the feasibility of gene therapy using adenoviral vectors in the nasal epithelium of such patients.

Methods. An adenoviral vector containing the normal CFTR complementary DNA in four logarithmically increasing doses (estimated multiplicity of infection, 1, 10, 100 , and 1000), or vehicle alone, was administered in a randomized, blinded fashion to the nasal epithelium of 12 patients with cystic fibrosis. Gene transfer was quantitated by molecular techniques that detected the expression of CFTR messenger RNA and by functional measurements of transepithelial potential differences (PDs) to assess abnormalities of ion transport specific to cystic fibrosis. The safety of this treatment was monitored by nasal
\end{abstract}

$\mathrm{C}$ YSTIC fibrosis is a recessive genetic disease caused by mutations in the cystic fibrosis transmembrane conductance regulator $(C F T R)$ gene. ${ }^{1-4}$ The normal CFTR gene codes for a protein (CFTR) that plays a key part in epithelial transport of salt and water. ${ }^{5,6}$ Mutations in CFTR result in abnormal secretions that obstruct and ultimately damage epithelium in many areas of the body. ${ }^{7}$

The principal cause of death among patients with cystic fibrosis is lung disease. Patients who are homozygous for mutations in the CFTR gene have defective cyclic AMP (cAMP)-regulated secretion of chloride $^{8,9}$ and elevated absorption of sodium ${ }^{10}$ in the airway epithelium, which thicken airway secretions, impair mucociliary clearance, and produce chronic bacterial infection of the airways. ${ }^{5-7,11}$ Carriers of a mutation in

From the Department of Medicine, Cystic Fibrosis-Pulmonary Research and Treatment Center (M.R.K., K.W.H., Z.Z., J.C.O., K.R.J., L.G.J., R.C.B.), and the Departments of Pediatrics (T.L.N., P.-C.H., M.W.L.) and Biostatistics (L.J.E.), School of Public Health, University of North Carolina, Chapel Hill; and the Institute for Human Gene Therapy and the Department of Molecular and Cellular Engineering, University of Pennsylvania, Philadelphia (J.F.E., M.G., J.M.W.). Address reprint requests to Dr. Knowles at the Cystic Fibrosis-Pulmonary Research and Treatment Center, 724 Burnett-Womack Bldg., CB 7020, University of North Carolina at Chapel Hill, Chapel Hill, NC 27599-7020.

Supported by grants from the Cystic Fibrosis Foundation (R026 and R881), the National Institute of Diabetes and Digestive and Kidney Diseases (P30 DK47757), the National Heart, Lung, and Blood Institute (HL42384 and HL51818), and the National Institutes of Health (RR00046).

Dr. Wilson and Ms. Grossman hold equity in Genova, Inc., a company involved in the development of gene-transfer technology. lavage and biopsy to assess inflammation and vector replication.

Results. The adenoviral vector was detected in nasal-lavage fluid by culture, the polymerase chain reaction (PCR), or both in a dose-dependent fashion for up to eight days after vector administration. There was molecular evidence of gene transfer by reverse-transcriptase PCR assays or in situ hybridization in five of six patients treated at the two highest doses. However, the percentage of epithelial cells transfected by the vector was very low ( $<1$ percent), and measurement of PD across the epithelium revealed no significant restoration of chloride transport or normalization of sodium transport. At the lower doses of vector, there were no toxic effects. However, at the highest dose there was mucosal inflammation in two of three patients.

Conclusions. In patients with cystic fibrosis, adenoviral-vector-mediated transfer of the CFTR gene did not correct functional defects in nasal epithelium, and local inflammatory responses limited the dose of adenovirus that could be administered to overcome the inefficiency of gene transfer. (N Engl J Med 1995;333:823-31.)

the CFTR gene do not have lung disease, which indicates that a single copy of the normal CFTR gene is sufficient for normal defense of the lung. The transfer of a single copy of normal CFTR into all epithelial cells affected by cystic fibrosis might be expected to correct airway function.

We performed a double-blind, vehicle-controlled study to assess the efficacy and safety of gene transfer to treat disease of the airways associated with cystic fibrosis. An adenoviral vector was selected for this study because of its reportedly high efficiency in gene transfer in both animal models ${ }^{12}$ and preclinical studies of human airway epithelium in vitro. ${ }^{13}$ The study used a dose-escalation protocol, in which the dose was defined with reference to previous studies ${ }^{14,15}$ by the estimated multiplicity of infection (the number of infectious adenoviral vectors delivered per airway epithelial cell). We confined our treatment to the nasal epithelium, which has morphologic features ${ }^{16}$ and cystic fibrosis-specific defects of ion transport similar to those of the lower airways, ${ }^{17}$ because of concern about safety generated in preclinical studies in which lung tissue was treated with adenoviral vector, ${ }^{18-20}$ and also because efficacy can be tested accurately and repeatedly at this site.

\section{METHODS}

This protocol was approved by the Committee for Protection of the Rights of Human Subjects, the Recombinant Advisory Commit- 
tee of the National Institutes of Health, and the Food and Drug Administration..$^{21}$ Additional information about the methods used is available from the National Auxiliary Publications Service (NAPS).*

\section{Study Subjects}

Twelve patients with stable pulmonary disease (mean $[ \pm \mathrm{SE}]$ forced expiratory volume in one second, $65.0 \pm 6.9$ percent of the predicted value) and pancreatic exocrine insufficiency were studied (Table 1). All were seropositive for adenovirus. ${ }^{22}$ The women had negative pregnancy tests and used contraceptive methods. Informed consent was obtained from all patients. ${ }^{21}$

\section{Gene-Transfer Vector}

We used a replication-defective adenovirus serotype 5 vector with a strong enhancer (cytomegalovirus)-promoter (chicken $\beta$-actin [CB]) (Ad5-CB-CFTR, recently designated H5.020CBCFTR) ${ }^{21}$ to express the CFTR complementary DNA (cDNA). Three lots of the adenoviral vector with particle:plaque-forming unit ratios ranging from 20:1 to 50:1 were produced by Good Manufacturing Practices at the Institute for Human Gene Therapy (University of Pennsylvania) and shipped frozen $\left(-70^{\circ} \mathrm{C}\right)$ to the University of North Carolina at Chapel Hill. Each lot was efficacious for CFTR transduction by the Western blot assay and for chloride secretion in vitro, and vector was titered and shown to be efficacious (by the Western blot assay) after dilution with $2 \mathrm{ml}$ of 3 percent glycerol in phosphate-buffered saline (vehicle).

\section{Study Design}

\section{Dosage}

The adenoviral vector was administered to four cohorts of three patients each, in logarithmically increasing doses. The dose of a biologic vector is complex and may be described in terms of the concentration (in plaque-forming units per milliliter), the total dose (in plaque-forming units), and the estimated number of vectors administered per epithelial cell (the estimated multiplicity of infection) (Table 1). Two milliliters of vehicle or adenoviral vector was infused (for 30 minutes) under direct vision onto the inferior and medial surfaces of the inferior turbinate and the nasal floor (approximately $8 \mathrm{~cm}^{2}$, or $2 \times 10^{7}$ surface epithelial cells ${ }^{23}$ ) of the right nostril, with the subject in a right lateral recumbent position. After treatment, the subject remained in that position for an additional 20 minutes. The subject was then repositioned in the left lateral recumbent position, and the left nostril was treated with the alternative solution. Dosing-simulation studies indicated that $58 \pm 4$ percent of the instilled solution remained in the nose for 50 minutes. The identity of the instilled solutions was known to only one investigator.

\section{Detection of Vector}

We monitored for residual adenoviral vector in urine samples and samples obtained with a swab from the nose, pharynx, and rectum by viral culture of 293 cells $^{21}$ and by a nested polymerase chain reaction (PCR) using primers that amplify the L3 region of the adenovirus and sequences of CFTR specific to the vector.

\section{Safety}

We monitored symptoms, vital signs, and blood counts and inspected the nose visually each day. Chest radiography, blood-chemistry testing, and spirometry were performed at the beginning and end of the study. Serum titers of adenoviral antibody were measured before and 21 days after treatment. ${ }^{22}$ Nasal-lavage fluid was analyzed

*See NAPS document no. 05245 for seven pages of supplementary material. Order from NAPS c/o Microfiche Publications, P.O. Box 3513, Grand Central Station, New York, NY 10163-3513. Remit in advance (in U.S. funds only) $\$ 7.75$ for photocopies or $\$ 4$ for microfiche. Outside the U.S. and Canada, add postage of $\$ 4.50$ ( $\$ 1.75$ for microfiche postage). There is a $\$ 15$ invoicing charge for all orders filled before payment.
Table 1. Study Design and Dosage of Adenoviral Vector.

\begin{tabular}{|c|c|c|c|c|c|c|}
\hline \multirow[t]{2}{*}{$\begin{array}{l}\text { Patient } \\
\text { No. }\end{array}$} & \multirow[t]{2}{*}{$\begin{array}{c}\text { SeX/AGE } \\
\text { (YR) }\end{array}$} & \multirow[t]{2}{*}{ GENOTYPE* } & \multicolumn{4}{|c|}{ ADENOVIRAL VECTOR } \\
\hline & & & $\begin{array}{l}\text { CONCEN- } \\
\text { TRATION } \\
\text { (pfu/ml) }\end{array}$ & $\begin{array}{c}\text { VOLUME } \\
(\mathrm{ml})\end{array}$ & $\begin{array}{l}\text { DOSE } \\
(\mathrm{pfu})\end{array}$ & $\begin{array}{l}\text { ESTIMATED } \\
\text { MULTIPLICITY } \\
\text { OF INFECTION }\end{array}$ \\
\hline Cohort 1 & & & $10^{7}$ & 2 & $2 \times 10^{7}$ & 1 \\
\hline 1 & $F / 25$ & $\Delta F_{508} / \Delta F_{508}$ & & & & \\
\hline 2 & $F / 39$ & $\Delta F_{508} / \Delta F_{508}$ & & & & \\
\hline 3 & $\mathrm{M} / 44$ & $\Delta F_{58} / N 1303 \mathrm{~K}$ & & & & \\
\hline Cohort 2 & & & $10^{8}$ & 2 & $2 \times 10^{8}$ & 10 \\
\hline 4 & $\mathrm{M} / 23$ & $\Delta F_{508} / \Delta F_{508}$ & & & & \\
\hline 5 & $\mathrm{~F} / 32$ & $\Delta F_{508} / \Delta F_{508}$ & & & & \\
\hline 6 & $\mathrm{M} / 21$ & $\bar{\Delta} F_{508} /$ Unknown & & & & \\
\hline Cohort 3 & & & $10^{9}$ & 2 & $2 \times 10^{9}$ & 100 \\
\hline 7 & $F / 24$ & $\Delta F_{508} / R 347 P$ & & & & \\
\hline 8 & $\mathrm{~F} / 34$ & $\Delta F_{508} / \Delta F_{508}$ & & & & \\
\hline 9 & $F / 40$ & $\Delta F_{508} / \Delta F_{508}$ & & & & \\
\hline Cohort 4 & & & $10^{10}$ & 2 & $2 \times 10^{10}$ & 1000 \\
\hline 10 & $\mathrm{~F} / 19$ & $\Delta F_{508} / \Delta F_{508}$ & & & & \\
\hline 11 & $\mathrm{M} / 19$ & $\Delta F_{508} / R 347 P$ & & & & \\
\hline 12 & $\mathrm{M} / 29$ & $\Delta F_{508} / \Delta F_{508}$ & & & & \\
\hline
\end{tabular}

${ }^{*} N 1303 \mathrm{~K}$ indicates a substitution of lysine for asparagine at amino acid position 1303, and $R 347 P$ a substitution of proline for arginine at position 347 .

daily for total cell counts (by hemocytometry), differential cell counts (in cytospin preparations), and the presence of cytokines (interleukin- $\beta$, interleukin- 6 , interleukin-8, and interleukin-10) and albu$\min .{ }^{24,25}$ Six days after treatment, biopsy specimens from the inferior turbinates were obtained, snap-frozen (in liquid nitrogen), and analyzed for inflammatory cell infiltrates. ${ }^{26}$

\section{Efficacy of Gene Transfer}

A reverse-transcriptase PCR assay of DNase-treated RNA from scrape-biopsy specimens of nasal epithelium obtained 6 and 21 days after dosing was performed ${ }^{27}$; vector-specific CFTR messenger RNA (mRNA) was amplified with primers across the junction of $3^{\prime}$ CFTR and untranslated viral sequences. In situ hybridization was performed with riboprobes specific for expressed vector sequences. ${ }^{28}$

The functional efficacy of the vector treatment was assayed by measuring the potential difference (PD), or voltage, across the nasal epithelium on 3 separate days before treatment, then daily for up to 14 days, and on day 21 after treatment. ${ }^{16,17,29}$ The protocol measured the basal PD (an index of sodium transport and mucosal integrity) and indexes of sodium transport (the basal PD and the degree of inhibition by a sodium-channel blocker, amiloride $\left[10^{-4} \mathrm{M}\right]$ ); basal chloride permeability (the response to perfusion with a chloride-free solution containing amiloride); cAMP-regulated (CFTR) secretion of chloride (the response to isoproterenol $\left[10^{-5} \mathrm{M}\right]$ in the perfusate in the presence of a chloride-free solution); and the capacity of the epithelium to secrete chloride (the effect of ATP $\left[10^{-4} \mathrm{M}\right]$ in the chloride-free perfusate on calcium-mediated chloride secretion ${ }^{29}$ ). PD was measured under the inferior turbinate (normal epithelium), the nasal floor, and the medial surface (metaplastic epithelium) of the inferior turbinate. ${ }^{16}$

\section{Statistical Analysis}

The primary analysis of the effects of treatment on nasal PD used a mixed model to fit repeated measures of the values obtained from days 1 through 6 after treatment with vehicle or adenoviral vector (the post-treatment values), using the base-line values (those obtained from day 5 before treatment to the day of treatment) as predictive variables in each cohort. ${ }^{30}$ The secondary analysis compared the mean base-line and post-treatment values by paired t-tests in each cohort. Each analysis yielded the same outcome. Mean baseline and post-treatment concentrations of inflammatory cells and mediators in nasal-lavage fluid were compared by paired t-tests. Scores for inflammatory-cell infiltrates in the biopsy specimens treated with vehicle were compared with those in the specimens treated with ad- 

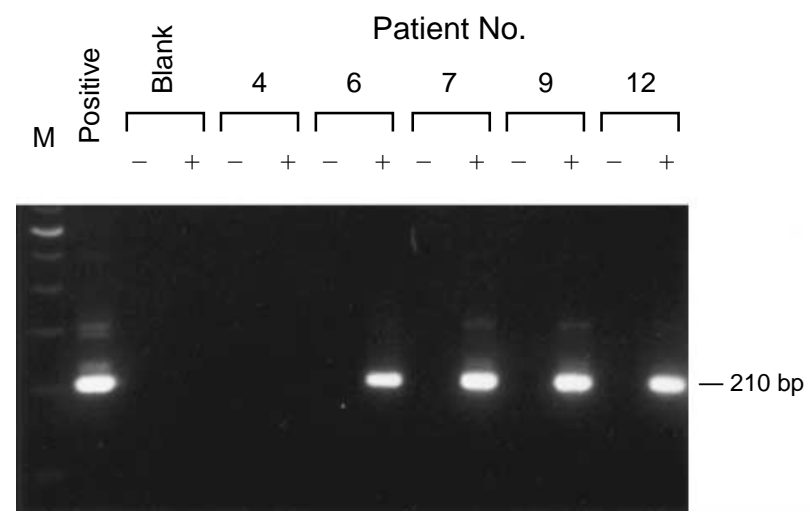

Figure 1. Reverse-Transcriptase PCR Assays for AdenoviralVector-Mediated Expression of CFTR mRNA in the Nasal Epithelium of Patients with Cystic Fibrosis.

Nasal epithelial cells were obtained by curette biopsy. RNA was extracted, treated with DNase, and exposed to reverse transcriptase $(+)$ or buffer $(-)$. A nested PCR was performed, and the products were resolved on 3 percent NuSieve agarose gels and stained with ethidium bromide. The results in five patients who received various doses of vector (Patients 4 and 6 from cohort 2, Patients 7 and 9 from cohort 3, and Patient 12 from cohort 4) are shown. Viral DNA (from the adenoviral vector) and water were added as a template for the positive and blank controls, respectively. The 210-base-pair (bp) vector-specific PCR product for CFTR mRNA is shown. M denotes the molecularweight marker.

enoviral vector by paired t-tests. $\mathrm{P}$ values of less than 0.05 were considered to indicate statistical significance.

\section{RESUlts}

\section{Detection of Vector}

\section{Culture}

Vector was routinely cultured from samples obtained 20 minutes after dosing from nostrils dosed with adenoviral vector, and for up to four days after higher doses (estimated multiplicity of infection, $\geqslant 100)$. One patient (Patient 11; estimated multiplicity of infection, 1000) had positive cultures from the vehicle-dosed nostril on day 1 and from rectal samples obtained one and two days after dosing. Additional data on individual patients are available from NAPS.*

\section{PCR}

Adenoviral-vector DNA was detected by PCR in samples obtained from the dosed nostrils for two to eight days after the administration of higher doses (estimated multiplicity of infection, $\geqslant 100)$. Vector DNA was detected in the vehicle-dosed nostrils of two patients (Patients 4 and 10) one and four days, respectively, after dosing, and from the pharynx of two patients (Patients 8 and 10) two days after dosing. In urine samples, two patients (Patients 2 and 8) had PCR products compatible with shedding of wild-type adenoviral DNA (L3/E1a-positive, CFTR-negative). ${ }^{31,32}$ One patient (Patient 4) was positive by PCR for L3 but not for E1a or CFTR on day 1 after treatment, making it impossible to distinguish between wild-type adenoviral DNA and the degraded vector.

\section{Molecular Assessment of Efficacy}

\section{Reverse-Transcriptase PCR Assay}

Figure 1 shows the PCR product (210 base pairs [bp]) of vector-expressed CFTR mRNA from inferiorturbinate epithelium obtained six days after the administration of adenoviral vector; vector-specific products were observed in several samples containing reverse transcriptase. The summary data (Table 2) show that only subjects who received the higher doses expressed vector-specific mRNA. No subject had a positive reverse-transcriptase PCR product from samples obtained three weeks after treatment. Samples from the side of the nose on which vehicle was administered were negative.

\section{In Situ Hybridization}

Biopsy specimens from the six subjects given the higher doses (cohorts 3 and 4; estimated multiplicity of infection, $\geqslant 100$ ) were studied. Previous studies and the positive controls used in this study (CFPAC cells) indicated that in situ signals could be detected in single cells probed for CFTR mRNA expressed in response to the strong CB promoter. ${ }^{33}$ Approximately 14,000 cells were examined in two sections from a biopsy specimen. No in situ signal was detected in specimens from five of six subjects. In one patient who received the highest dose (Patient 11), four patchy areas (i.e., containing approximately 15 to 20 cells) of gene transfer were detected; two were in regions of intact airway ep-

Table 2. Presence or Absence of Adenoviral-Vector CFTR mRNA in Samples of $\mathrm{Na}$ sal Epithelium Obtained Six Days after Treatment.*

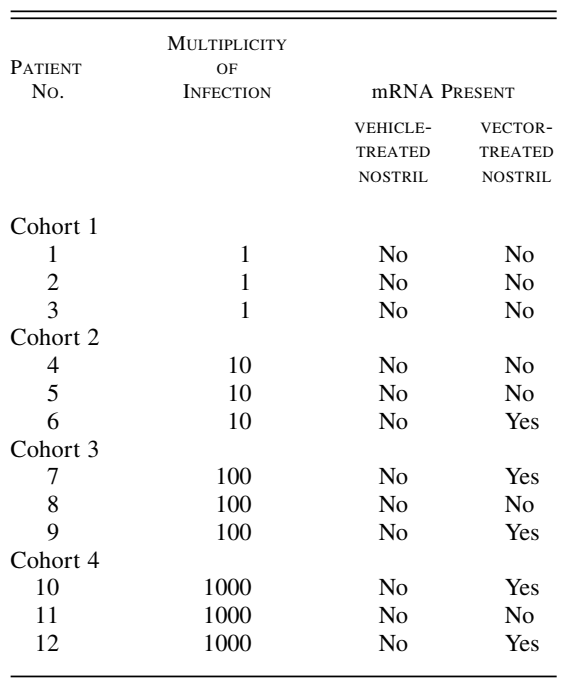

*A vector-specific reverse-transcriptase PCR assay was used to detect CFTR mRNA. 
ithelium, and two were in areas of damage, including expression in the submucosa. No signal was detected in the nostrils treated with vector when the samples were treated with RNase or studied with sense probes, nor was an antisense signal detected in the nostrils treated with vehicle.

\section{Assessment of Biologic Efficacy by Measurements of PD}

The measurements of PD under the inferior surface of the turbinate (in normal ciliated epithelium) are summarized below.

\section{Basal $P D$}

A total of 1440 PD measurements were made (Fig. 2). There was no change in basal PD among patients who were exposed to vector at an estimated multiplicity of infection of 1,10 , or 100 (cohorts 1, 2, and 3). In contrast, the mean basal PD decreased by $15.1 \pm 1.6$ $\mathrm{mV}$ after the administration of vector at the highest dose (cohort 4, including Patients 10, 11, and 12; estimated multiplicity of infection, 1000). There was no significant change in the PD of epithelium treated with vehicle in any cohort.

\section{Inhibition by Amiloride}

There was no change in the percentage of inhibition of the basal PD with amiloride, a sodium-channel blocker, after treatment with either vector or vehicle in any cohort (inhibition in cohort 4, 69.5 \pm 2.7 percent before treatment with vector and $68.5 \pm 2.1$
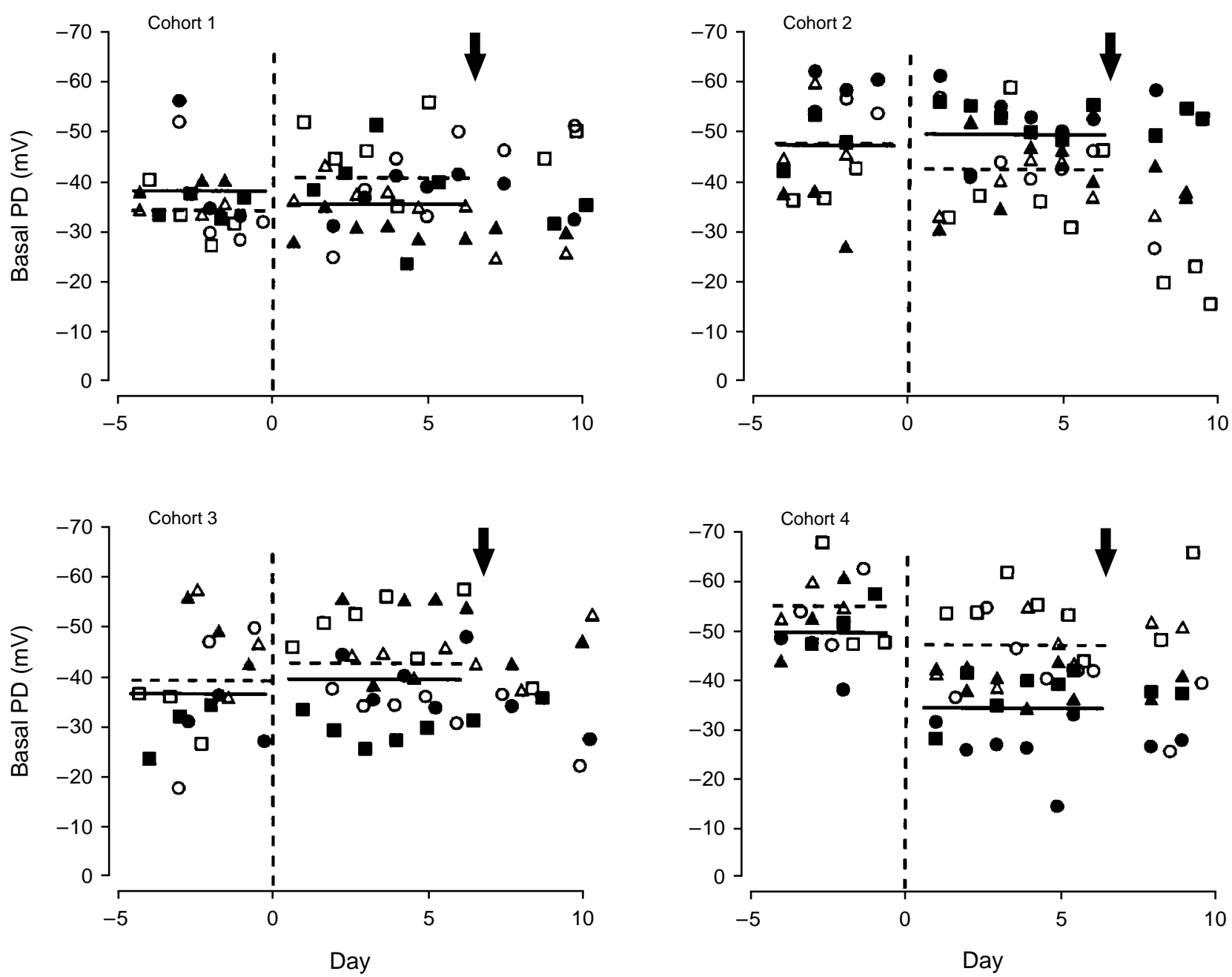

Figure 2. Basal Transepithelial Potential Difference (PD) before and after the Administration of Adenoviral Vector or Vehicle in Each Cohort.

Individual measurements of the basal PD were made three times before the administration of adenoviral vector or vehicle (dashed vertical lines, day 0 ) and serially for up to 21 days after treatment. The three patients in each cohort are designated by three symbols $(\square, \bigcirc$, and $\triangle$ ); the data for the nostrils in which vehicle was administered are designated by open symbols, and those for the nostrils in which vector was administered are designated by solid symbols. Horizontal lines (dashed for vehicle, solid for vector) indicate the mean values before treatment and on days 1 through 6 after treatment (before biopsy). Arrows indicate the time of biopsy. $\mathrm{P}=0.02$ for the difference in the mean values obtained before and after treatment with vector in the highest-dose cohort (cohort 4). 
percent afterward; estimated multiplicity of infection, 1000).

\section{Basal Chloride Permeability}

There were no systematic changes in PD after chloride substitution, even in the highest-dose cohort (change in $\mathrm{PD}$ in nostrils treated with vector in cohort $4,5.8 \pm 0.7$ $\mathrm{mV}$ before treatment and $4.5 \pm 0.4 \mathrm{mV}$ afterward; in nostrils treated with vehicle, $4.7 \pm 0.6$ and $4.5 \pm 0.5 \mathrm{mV}$, respectively).

\section{Isoproterenol-Regulated Chloride Secretion}

We found no evidence of isoproterenol (cAMP)induced increases in PD (chloride secretion), even in the highest-dose cohort (change in nostrils treated with vector in cohort $4,0.2 \pm 0.3 \mathrm{mV}$ before treatment and $-0.2 \pm 0.6 \mathrm{mV}$ afterward; in nostrils treated with vehicle, $0.8 \pm 0.4$ and $0.3 \pm 0.3 \mathrm{mV}$, respectively).

\section{Combined Response to Chloride Substitution and Isoproterenol}

The change in nasal PD in amiloride-treated epithelium in response to both chloride substitution and treatment with isoproterenol best discriminates patients with cystic fibrosis from normal subjects ${ }^{29,34}$ (Fig. 3). The individual data points, relative to previously published values from normal subjects ${ }^{29}$ (shaded area in Fig. 3), are shown for each cohort. There were no significant changes in PD, even in the highest-dose cohort (change in PD with vector in cohort 4, 4.9 \pm 0.3
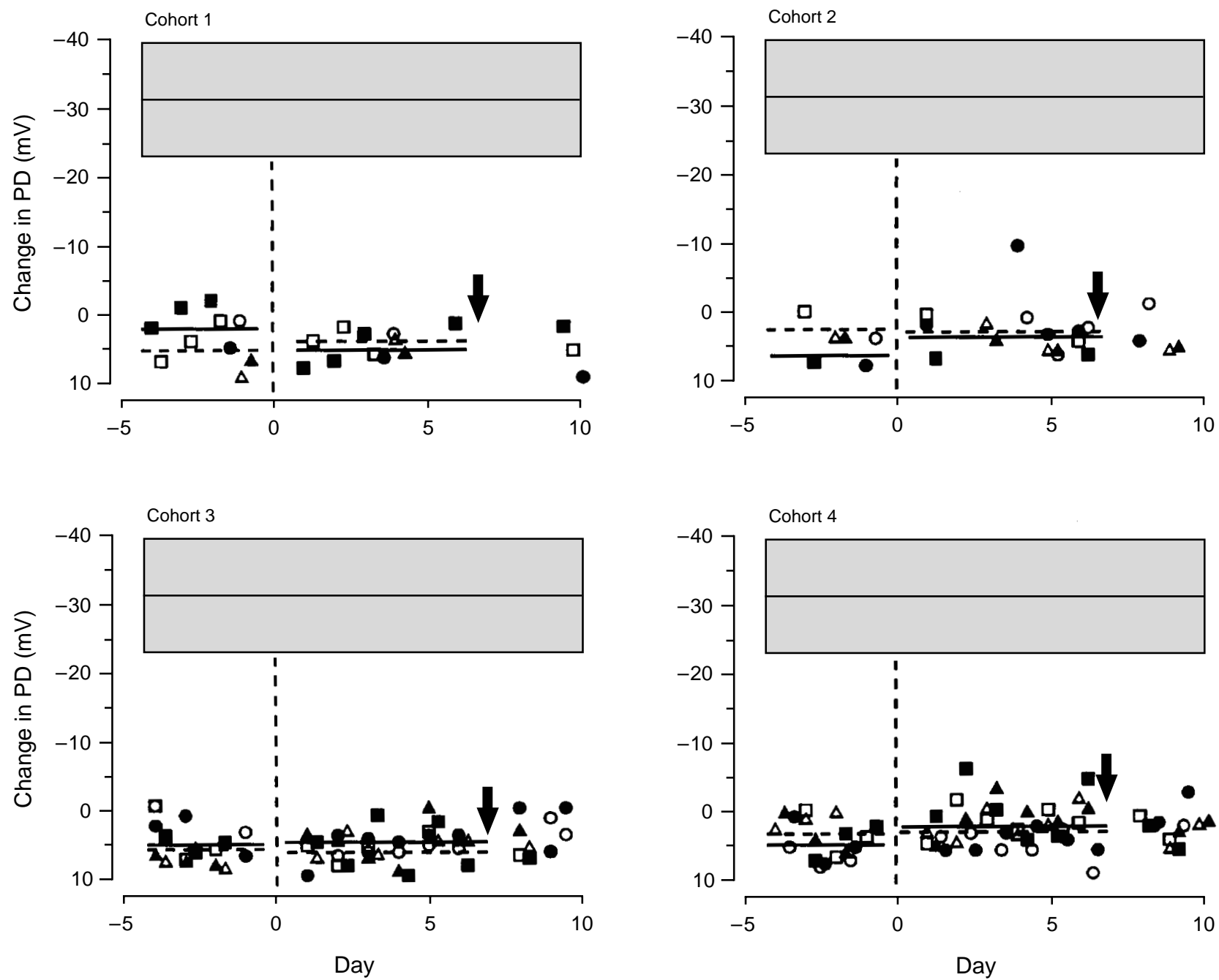

Figure 3. Assay of Nasal PD to Determine the Extent of CFTR-Mediated Chloride Transport before and after the Administration of Adenoviral Vector or Vehicle in Each Cohort.

The combined change in transepithelial PD in amiloride-pretreated nasal epithelium after chloride-free perfusion (with replacement by gluconate) and the administration of isoproterenol is shown plotted against time in each cohort. The intervals measured, the time of administration (vertical dashed lines), symbols denoting patients and type of treatment (open for vehicle, solid for vector), arrows indicating the time of biopsy, and horizontal lines (dashed for vehicle, solid for vector) are as described in the legend to Figure 2. The mean $( \pm S D)$ changes in the PD of normal subjects ${ }^{29}$ in response to the chloride-substitution-isoproterenol maneuver are shown at the top of each panel as solid horizontal lines and shaded areas, respectively. 
$\mathrm{mV}$ before treatment and $2.0 \pm 1.7 \mathrm{mV}$ afterward; with vehicle, $4.6 \pm 1.6$ and $3.8 \pm 1.4 \mathrm{mV}$, respectively).

\section{ATP-Regulated Chloride Secretion}

Large ATP-induced increases in PD, reflecting calcium-mediated chloride secretion, were detected in all cohorts before treatment (change in PD with vehicle, $-19.9 \pm 2.7 \mathrm{mV}$; with vector, $-20.6 \pm 2.4 \mathrm{mV}$ ), and they persisted after treatment $(-20.8 \pm 2.3$ and $-18.7 \pm 2.4$ $\mathrm{mV}$, respectively).

Data similar to those given above for normal epithelium were obtained in each cohort for measurements of PD on the medial surface of the inferior turbinate (metaplastic epithelium).

\section{Safety}

No patient had significant changes in vital signs, complete blood count, blood chemistry, chest radiographs, or results of spirometric analysis. No patient receiving doses of adenoviral vector with an estimated multiplicity of infection of 1,10 , or 100 (cohorts 1, 2, and 3) had local symptoms or signs. Two patients (Patients 10 and 12) in cohort 4 (the highest-dose group) had symptoms and signs of toxic effects within 12 to 24 hours of the administration of the dose. One patient (Patient 10) had an earache and an inflamed tympanic membrane; the other (Patient 12) had jaw pain and mandibular-angle (nodal) tenderness; these symptoms were all ipsilateral to the site of administration of vector. Visual inspection by an ear, nose, and throat specialist who was unaware of the dosing schedule and the symptoms of the patients revealed unilateral induration of the nasal mucosa and increases in mucosal sensitivity and secretions that were confined to the nostril treated with vector. Maximal symptoms and signs occurred after 48 to 96 hours, and there was complete resolution within three weeks. Further information on individual patients is available from NAPS.*

\section{Nasal Lavage and Measurements of Cells and Cytokines}

No difference in the total cell count or in the quantity of interleukin- $1 \beta$, interleukin- 6 , interleukin-8, and interleukin-10 in nasal-lavage fluid was noted on days 1 through 6 after the administration of vector or vehicle in any cohort. The nostrils treated with vector in the highest-dose cohort had a greater increase in the total number of cells, neutrophils, interleukin-6, and interleukin-8 in response to the nasal biopsy than did the nostrils treated with vehicle, suggesting that the adenoviral vector primed the epithelium for an inflammatory response.

\section{Albumin in Nasal-Lavage Fluid}

There was no change in the albumin concentration in nasal-lavage fluid in Patients 1 through 9 (cohorts 1,

*See NAPS document no. 05245 for seven pages of supplementary material. Order from NAPS c/o Microfiche Publications, P.O. Box 3513, Grand Central Station, New York, NY 10163-3513. Remit in advance (in U.S. funds only) \$7.75 for photocopies or $\$ 4$ for microfiche. Outside the U.S. and Canada, add postage of $\$ 4.50$ ( $\$ 1.75$ for microfiche postage). There is a $\$ 15$ invoicing charge for all orders filled before payment.

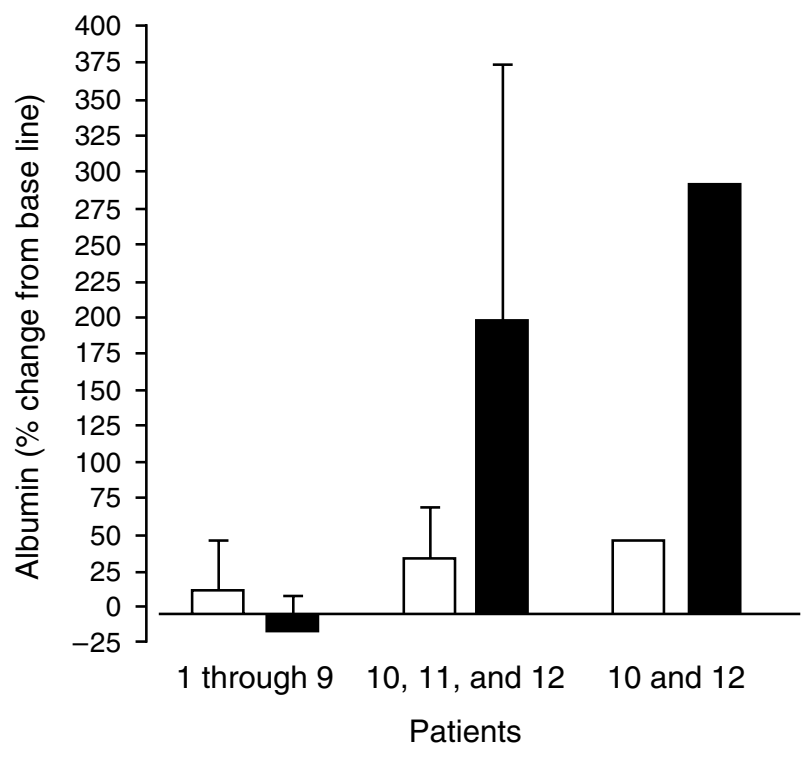

Figure 4. Mean $( \pm S E)$ Change from Base Line in the Albumin Content of Nasal-Lavage Fluid during the Six Days after the Administration of Vehicle (Open Bars) or Vector (Solid Bars), Expressed as the Percentage of Change from the Values before Treatment.

The values for cohorts 1,2, and 3 (Patients 1 through 9) and cohort 4 (Patients 10,11, and 12) are shown separately. The two patients (Patients 10 and 12) in cohort 4 who had signs and symptoms of nasal inflammation or damage are shown so that their data may be compared with the mean data for cohort 4 . The base-line levels of albumin in nasal-lavage fluid in each group shown were as follows: cohorts 1,2 , and 3, $12.0 \mu \mathrm{g}$ per milliliter in the vehicle-treated nostril and $12.2 \mu \mathrm{g}$ per milliliter in the vector-treated nostril; cohort 4, 2.4 and $6.4 \mu \mathrm{g}$ per milliliter; and Patients 10 and $12,2.5$ and $4.2 \mu \mathrm{g}$ per milliliter.

2, and 3) after the administration of either vector or vehicle on days 1 through 6 , as compared with the base-line values (Fig. 4). In contrast, in the highestdose cohort (cohort 4), the albumin concentration doubled in the nostrils treated with vector, but not in those treated with vehicle. This increase was approximately threefold in the two symptomatic patients (Patients 10 and 12).

\section{Histopathological Analysis of Nasal-Biopsy Specimens}

There was no difference in the number of inflammatory cells in the epithelium or submucosa between the biopsy specimens from the nostrils treated with adenoviral vector and those treated with vehicle in any cohort.

\section{Serum Antibodies to Adenovirus}

One patient (Patient 10) in the highest-dose cohort had an increase (from 1:80 to 1:1280) in the titer of neutralizing antibody 21 days after the administration of the vector.

\section{Discussion}

In this double-blinded, vehicle-controlled trial of adenoviral vector in patients with cystic fibrosis, we found molecular evidence of low-efficiency gene trans- 
fer and expression of the normal CFTR mRNA in nasal epithelium, but there was no significant functional correction of abnormalities in ion transport. The absence of adenoviral-vector tropism for surface columnar cells, ${ }^{35}$ which normally express CFTR, ${ }^{36}$ explains this failure. This problem cannot be overcome by simply increasing the dose of the vector, because the highest dose we used (with an estimated multiplicity of infection of 1000) was associated with inflammatory responses in two of three patients; in addition, studies in animals indicate a wide spectrum of toxic effects at higher doses. ${ }^{18-20}$

Careful attention was paid to the design, production, and administration of the vector we used. With its strong promoter, this vector was completely effective in correcting cystic fibrosis-associated defects of chloride $^{35}$ and sodium transport in the airway epithelium in vitro. ${ }^{37}$ Three separate lots of vector were produced $^{21,38}$ and tested for the titer and for the efficacy of CFTR gene transfer at two independent sites before their use. The adequacy of vector administration and the viability of the vector were confirmed by its detection in the nostril treated with vector up to eight days after the administration of the dose.

Two outcome variables were measured with respect to efficacy and were grouped on the basis of dosage. In the two lower-dose cohorts (cohorts 1 and 2; estimated multiplicity of infection, 1 and 10 , respectively), we found little evidence of adenoviral-vector-mediated gene transfer. Only one of six patients was positive for gene transfer by the reverse-transcriptase PCR assay. This assay is sensitive to as few as 5 cells expressing vector CFTR mRNA among 500,000 cells not expressing this mRNA (0.001 percent); thus, the negative PGR data in these cohorts indicated that virtually no gene transfer occurred. ${ }^{39}$ The lack of functional correction of PD is consistent with this conclusion.

In the two higher-dose cohorts (cohorts 3 and 4; estimated multiplicity of infection, 100 and 1000, respectively), there was more evidence of gene transfer by the reverse-transcriptase PGR assay (four of six patients were positive). However, in situ hybridization, which is about one order of magnitude less sensitive than the PCR assay, detected expression in only one of these six patients, and the percentage of epithelial cells expressing CFTR mRNA in this one patient was low (less than 1 percent of the total number). Previous studies have shown that CFTR expression in 3 to 6 percent of the cells in the cystic fibrosis epithelium is required to correct the defect in chloride secretion. ${ }^{35,40}$ The PD protocols that are sensitive measures of CFTRmediated chloride transport (e.g., the combined response to chloride substitution and isoproterenol) detected no systematic evidence of gene transfer, a finding consistent with an efficiency of gene transfer of less than 1 percent (Fig. 3).

Three data points slightly above the range for cystic fibrosis in the highest-dose cohort could reflect patchy gene transfer or nonspecific effects of isoproterenol to activate a calcium-regulated chloride pathway in in- flamed tissues. The relation between the efficiency of correction and the restoration of sodium transport is different from that for chloride, with virtually all cells requiring functional correction in order for the normalization of sodium transport to occur. There was no change in the percentage of inhibition of PD by amiloride in cohorts 3 and 4 to suggest a correction of sodium transport. Thus, in these cohorts vector-mediated gene transfer was detected, but its efficiency was too low for either the chloride or the sodium-transport defect associated with cystic fibrosis to be corrected.

No evidence of systemic toxic effects was noted in any patient, and no local toxic effects were noted in the cohorts receiving the three lowest doses. However, two of the three patients in the highest-dose cohort had symptoms and signs of local toxic effects in the mucosa, reduced basal PDs, and an increased flux of albumin into the fluid subsequently obtained by lavage from the nostrils treated with vector - observations consistent with epithelial damage. ${ }^{29,41,42}$ The syndrome was not associated with increased numbers of white cells or concentrations of cytokines in nasal-lavage fluid or with the cellular infiltrates associated with more chronic toxic effects (lasting 3 to 21 days) that have been identified in studies in animals. ${ }^{18-20}$ The rapid onset of the syndrome, like the severe pulmonary inflammatory reaction to Ad-CFTR, a similar adenoviral vector, in a patient described by Crystal et al., ${ }^{15}$ coupled with recent studies in animals, ${ }^{43}$ suggests a neurogenic inflammatory cause.

Three observations were made that may pertain to the safety of the vector we used. First, there was dissemination of the vector - for example, to the pharynx and stool - at higher doses. Second, we detected vector DNA in the nasal cavity for up to eight days. The precise location of the vector in the epithelium is not known, and therefore the possibility of transmission or recombination of vector with wild-type adenovirus cannot be discounted. ${ }^{21,44}$ Finally, we observed an increase in the serum antibody titer in one patient receiving the highest dose of vector, which may have implications for the safety of the vector (e.g., enhanced immunologic responses on subsequent treatment with vector), implications for the efficacy of repeated administration of vector, or both. ${ }^{19}$

Two unblinded trials of Ad-CFTR in patients with cystic fibrosis have been reported. We could not confirm the correction of the cystic fibrosis-associated nasal defect of chloride transport reported by Zabner et al. ${ }^{14}$ Our study paralleled their study with respect to the site of deposition, and we used a vector with a stronger promoter and used that vector in higher concentrations (1.5 to $3 \operatorname{logs}$ ). The discrepancy probably relates to the PD protocols used to measure efficacy. The protocol used by Zabner et al. does not readily discriminate between patients with cystic fibrosis and normal subjects, making it difficult to interpret the results. The chloride-free PD protocols used in this study are highly sensitive in such discrimination ${ }^{29,34}$ and can detect full or even partial correction of chlo- 
ride transport. This discrepancy highlights the need for standardized PD protocols and for complementary molecular and morphologic methods of assessing gene transfer.

Crystal et al. ${ }^{15}$ reported no quantitative nasal bioelectric data, but they did report positive results of immunocytochemical analysis for CFTR in one of four patients after bronchial brushing of a region that had received transbronchoscopic doses of vector. The evidence of transduction in bronchial cells may possibly reflect an increased efficiency of gene transfer in lower airway epithelium as compared with nasal epithelium, as has been reported in rodents. ${ }^{12,18}$ Alternatively, damage to airway epithelium can substantially enhance gene transfer by abrading the relevant target cells (i.e., the surface columnar cells) and exposing the vector to basal cells, which are more easily transduced but do not normally express CFTR..$^{35}$ Thus, data pertaining to transduced epithelium from previously traumatized areas may not be representative of gene transfer to intact, undamaged epithelium, such as that treated in our study.

In summary, adenoviral-vector-mediated gene transfer to nasal epithelium affected by cystic fibrosis is inefficient. One potential strategy to overcome this problem would be to target adenoviral vectors to basal cells. Another would involve attempting to differentiate basal cells into columnar cells. A third would be to modify the vector itself so that it becomes tropic for columnar cells. If the nasal epithelium is typical of all human airway regions with respect to the observed inefficiency of adenoviral-vector-mediated gene transfer, it would appear prudent also to accelerate the development of alternative vectors, ${ }^{45}$ or to modify the adenoviral vectors, if gene transfer is to be successful in treating lungs in patients with cystic fibrosis.

We are indebted to K. Burns, C. Foy, J. Robinson, J. Winders, C.-H. Wong, and I. Wortman for expert technical assistance, to L. Dudus and H. Ye for assistance with the in situ hybridization studies, to P. Noone and W. Bennett for assistance with the dosing-simulation studies, to K. Kozarsky for assistance in the serologic testing for adenovirus by the Western blot assay, to L. Brown for editorial assistance, to the nursing staff of the General Clinical Research Center for expert patient care, and to the patients who participated in this challenging study.

\section{REFERENCES}

1. Riordan JR, Rommens JM, Kerem B, et al. Identification of the cystic fibrosis gene: cloning and characterization of complementary DNA. Science 1989;245:1006-73. [Erratum, Science 1989;245:1437.]

2. Rommens JM, Iannuzzi MC, Kerem B, et al. Identification of the cystic fibrosis gene: chromosome walking and jumping. Science 1989;245:105965.

3. Kerem B, Rommens JM, Buchanan JA, et al. Identification of the cystic fibrosis gene: genetic analysis. Science 1989;245:1073-80.

4. Collins FS. Cystic fibrosis: molecular biology and therapeutic implications. Science 1992;256:774-9.

5. Boucher RC. Human airway ion transport. Am J Respir Crit Care Med 1994;150:581-93.

6. Quinton PM. Cystic fibrosis: a disease in electrolyte transport. FASEB J 1990;4:2709-17.

7. Davis PB. Pathophysiology of the lung disease in cystic fibrosis. In: Davis PB, ed. Cystic fibrosis. Vol. 64 of Lung biology in health and disease. New York: Marcel Dekker, 1993:193-218.
8. Widdicombe JH, Welsh MJ, Finkbeiner WE. Cystic fibrosis decreases the apical membrane chloride permeability of monolayers cultured from cells of tracheal epithelium. Proc Natl Acad Sci U S A 1985;82:6167-71.

9. Stutts MJ, Cotton CU, Yankaskas JR, et al. Chloride uptake into cultured airway epithelial cells from cystic fibrosis patients and normal individuals. Proc Natl Acad Sci U S A 1985;82:6677-81.

10. Boucher RC, Stutts MJ, Knowles MR, Cantley L, Gatzy JT. $\mathrm{Na}^{+}$transport in cystic fibrosis respiratory epithelia: abnormal basal rate and response to adenylate cyclase activation. J Clin Invest 1986;78:1245-52.

11. Boat TF, Welsh MJ, Beaudet AL. Cystic fibrosis. In: Scriver CR, Beaudet AL, Sly WS, Valle D, eds. The metabolic basis of inherited disease. 6th ed. Vol. 2. New York: McGraw-Hill, 1989:2649-80.

12. Rosenfeld MA, Yoshimura K, Trapnell BC, et al. In vivo transfer of the human cystic fibrosis transmembrane conductance regulator gene to the airway epithelium. Cell 1992:68:143-55.

13. Zabner J, Couture LA, Smith AE, Welsh MJ. Correction of cAMP-stimulated fluid secretion in cystic fibrosis airway epithelia: efficiency of adenovirus-mediated gene transfer in vitro. Hum Gene Ther 1994;5:585-93.

14. Zabner J, Couture LA, Gregory RJ, Graham SM, Smith AE, Welsh MJ. Adenovirus-mediated gene transfer transiently corrects the chloride transport defect in nasal epithelia of patients with cystic fibrosis. Cell 1993;75:20716.

15. Crystal RG, McElvaney NG, Rosenfeld MA, et al. Administration of an adenovirus containing the human CFTR cDNA to the respiratory tract of individuals with cystic fibrosis. Nat Genet 1994;8:42-51.

16. Knowles MR, Carson JL, Collier AM, Gatzy JT, Boucher RC. Measurements of nasal transepithelial electric potential differences in normal human subjects in vivo. Am Rev Respir Dis 1981;124:484-90.

17. Knowles MR, Gatzy J, Boucher R. Increased bioelectric potential difference across respiratory epithelia in cystic fibrosis. N Engl J Med 1981;305: 1489-95.

18. Yang Y, Nunes FA, Berencsi K, Gonczol E, Engelhardt JF, Wilson JM. Inactivation of E2a in recombinant adenoviruses improves the prospect for gene therapy in cystic fibrosis. Nat Genet 1994;7:362-9.

19. Yei S, Mittereder N, Wert S, Whitsett JA, Wilmott RW, Trapnell BC. In vivo evaluation of the safety of adenovirus-mediated transfer of the human cystic fibrosis transmembrane conductance regulator cDNA to the lung. Hum Gene Ther 1994;5:731-44.

20. Simon RH, Engelhardt JF, Yang Y, et al. Adenovirus-mediated transfer of the CFTR gene to lung of nonhuman primates: toxicity study. Hum Gene Ther 1993;4:771-80.

21. Boucher RC, Knowles MR, Johnson LG, et al. Gene therapy for cystic fibrosis using E1-deleted adenovirus: a phase I trial in the nasal cavity: the University of North Carolina at Chapel Hill. Hum Gene Ther 1994;5:61539.

22. Hierholzer JC. Adenoviruses. In: Schmidt NJ, Emmons RW, eds. Diagnostic procedures for viral, rickettsial and chlamydial infections. 6th ed. Washington, D.C.: American Public Health Association, 1989:219-64.

23. Mercer RR, Russell ML, Roggli VL, Crapo JD. Cell number and distribution in human and rat airways. Am J Respir Cell Mol Biol 1994;10:613-24.

24. Noah TL, Henderson FW, Wortman IA, et al. Nasal cytokine production in viral acute respiratory infection of childhood. J Infect Dis 1995;171:584-92.

25. Peden DB, Swiersz M, Ohkubo K, Hahn B, Emery B, Kaliner MA. Nasal secretion of the ozone scavenger uric acid. Am Rev Respir Dis 1993;148: $455-61$

26. Curtis JL, Byrd PK, Warnock ML, Beck JM, Kaltreider HB. Pulmonary lymphocyte recruitment: depletion of $\mathrm{CD} 8+\mathrm{T}$ cells does not impair the pulmonary immune response to intratracheal antigen. Am J Respir Cell Mol Biol 1993;9:90-8

27. Highsmith WE, Burch LH, Zhou Z, et al. A novel mutation in the cystic fibrosis gene in patients with pulmonary disease but normal sweat chloride concentrations. N Engl J Med 1994;331:974-80.

28. Engelhardt JF, Yankaskas JR, Ernst SA, et al. Submucosal glands are the predominant site of CFTR expression in the human bronchus. Nat Genet 1992;2:240-8.

29. Knowles MR, Paradiso AM, Boucher RC. In vivo nasal potential difference: techniques and protocols for assessing efficacy of gene transfer in cystic fibrosis. Hum Gene Ther 1995;6:445-55.

30. Zeger SL, Liang KY. An overview of methods for the analysis of longitudinal data. Stat Med 1992;11:1825-39.

31. Stalder H, Hierholzer JC, Oxman MN. New human adenovirus (candidate adenovirus type 35 ) causing fatal disseminated infection in a renal transplant recipient. J Clin Microbiol 1977;6:257-65.

32. Mufson MA, Belshe RB. A review of adenoviruses in the etiology of acute hemorrhagic cystitis. J Urol 1976;115:191-4.

33. Engelhardt JF, Yankaskas JR, Wilson JM. In vivo retroviral gene transfer into human bronchial epithelia of xenografts. J Clin Invest 1992;90:2598607.

34. Middleton PG, Geddes DM, Alton EWFW. Protocols for in vivo measurement of the ion transport defects in cystic fibrosis nasal epithelium. Eur Respir J 1994;7:2050-6. 
35. Grubb BR, Pickles RJ, Ye H, et al. Inefficient gene transfer by adenovirus vector to cystic fibrosis airway epithelia of mice and humans. Nature 1994; 371:802-6.

36. Yankaskas JR, Suchindran H, Sarkadi B, Nettesheim P, Randell SH. Cystic fibrosis transmembrane conductance regulator (CFTR) protein is selectively expressed in ciliated airway epithelial cells. Am Rev Respir Dis 1993;147: Suppl:A26. abstract.

37. Johnson LG, Boyles SE, Wilson J, Boucher RC. Normalization of raised sodium absorption and raised calcium-mediated chloride secretion by adenovirus-mediated expression of cystic fibrosis transmembrane conductance regulator in primary human cystic fibrosis airway epithelial cells. J Clin Invest 1995;95:1377-82.

38. Wilson JM, Engelhardt JF, Grossman M, Simon RH, Yang Y. Gene therapy of cystic fibrosis lung disease using E1 deleted adenoviruses: a phase I trial. Hum Gene Ther 1994:5:501-19.

39. Johnson LG, Pickles RJ, Boyles SE, et al. In vitro assessment of variables affecting the efficiency and efficacy of adenovirus-mediated gene transfer to cystic fibrosis airway epithelia. Hum Gene Ther (in press).
40. Johnson LG, Olsen JC, Sarkadi B, Moore KL, Swanstrom R, Boucher RC. Efficiency of gene transfer for restoration of normal airway epithelial function in cystic fibrosis. Nat Genet 1992;2:21-5.

41. Naclerio RM, Proud D, Lichtenstein LM, et al. Kinins are generated during experimental rhinovirus colds. J Infect Dis 1988;157:133-42.

42. Henderson FW, Dubovi EJ, Harder S, Seal E Jr, Graham D. Experimental rhinovirus infection in human volunteers exposed to ozone. Am Rev Respir Dis $1988 ; 137: 1124-8$.

43. Piedimonte G, Pickles RJ, Lehmann JR, Costa DL, Boucher RC. Replication-deficient adenoviral vector for gene therapy exhibits a strong potentiating effect on airway neurogenic inflammation. Pediatr Pulmonol 1995; Suppl 12:224. abstract.

44. Bateman ED, Hayashi S, Kuwano K, Wilke TA, Hogg JC. Latent adenoviral infection in follicular bronchiectasis. Am J Respir Crit Care Med 1995;151: $170-6$.

45. Caplen NJ, Alton EWFW, Middleton PG, et al. Liposome-mediated CFTR gene transfer to the nasal epithelium of patients with cystic fibrosis. Nat Med 1995;1:39-46. 